\title{
Antrieb von morgen
}

\section{Liebe Leserin, lieber Leser,}

die MTZ-Tagung „Der Antrieb von morgen“ in Wolfsburg, seit über zehn Jahren mit Unterstützung von Volkswagen und Schaeffler etabliert, fand in diesem Jahr nicht statt. Sie wird ab 2017 wieder neu durchstarten. Die zunehmende Elektrifizierung des Antriebs und die zukünftig erforderlichen $\mathrm{CO}_{2}$-neutralen Kraftstoffe führen zu einer Komplexität in der Entwicklung von Antrieb und Gesamtfahrzeug, die eine nochmals gesteigerte systemische Herangehensweise an Planung, Prozesse und Abläufe erfordert. Vor diesem Hintergrund richten wir den „Antrieb von morgen“ gemeinsam mit den bisherigen Partnern um den Systemverbund von Verbrennungsmotor, Getriebe und Elektrifizierung herum neu aus. In diesem Heft finden Sie als Vorgeschmack eine Sonderstrecke zur Thematik der Tagung. Wir würden uns freuen, Sie am 25. und 26. Januar 2017 als Vortragende oder Besucher in Frankfurt am Main begrüßen zu dürfen.

Die Gesetzgebungen zu $\mathrm{CO}_{2}$-Emissionen und Luftqualität haben die Rahmenbedingungen für die Entwicklung zukünftiger Antriebe grundlegend verändert. Der gesellschaftliche Wertewandel führt dazu, dass zukünftig eines der entscheidenden Kriterien für Erfolg oder Misserfolg davon abhängen wird, wie stark der ökologische Fußabdruck eines Fahrzeugs und damit einer Marke sein wird. Die Einführung des WLTP wird die bisher weit geöffnete Schere zwischen Realverbrauch und Katalogverbrauch deutlich schließen. Sogenannte Worst-Case- $\mathrm{CO}_{2}$ Angaben werden Pflicht, individuelle $\mathrm{CO}_{2}$-Angaben für einzelne Fahrzeuge und Varianten sind erlaubt. Sonderausstattungen müssen dadurch optimiert werden. Längere Zyklusdauer, größere Beschleunigung und höhere Geschwindigkeiten bewerten einen deutlich realistischeren Fahrzyklus. Dadurch nimmt der Einfluss elektrischer Verbraucher ab, der Beitrag des Luftwiderstands jedoch erheblich zu.
Das Thema RDE ist sehr komplex, da die Rahmenbedingungen im Fahrbetrieb durch Umweltbedingungen, Route, Fahrstil und Kraftstoffe eine erhebliche Rolle spielen. RDE ist beim Nfz seit Jahren kein Thema mehr, wohl aber beim Pkw, weil hier ein enormer Leistungsüberschuss vorliegt. Der Einfluss des Fahrers ist deutlich größer als der Streckeneinfluss und bei den beliebten SUV noch viel stärker als bei anderen Fahrzeuggattungen. Es kann daher, um die RDE-Robustheit zu maximieren, nötig werden, auf Partikelfilter auch im Ottomotor zurückzugreifen. Angesichts dieser Ausgangslage stellt sich wieder die Frage, warum der Saubermann unter den Ottoantrieben, der CNG-Antrieb, noch immer ein Schattendasein fristet.

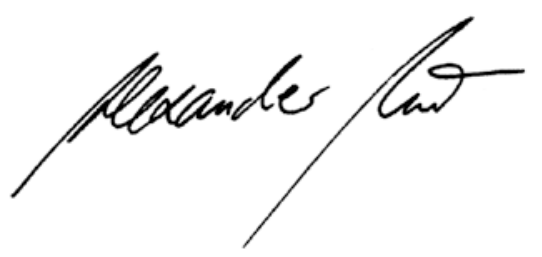

Dr. Alexander Heintzel Chefredakteur

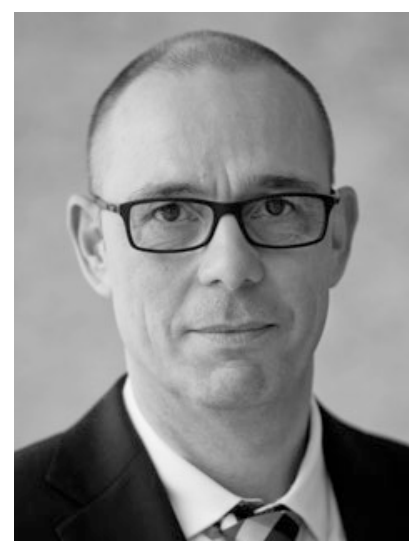

\section{INNOVATIV} D) E ZUVERLÄSSIG

Winkelmann Automotive ist einer der global führenden Zulieferer von Systemkomponenten für alle namhaften Automobilhersteller.

Mit unseren Produkten, die wir für unsere Kunden weltweit vor Ort entwickeln und produzieren, setzen wir Maßstäbe in Bezug auf Innovation und Qualität.

Dabei fertigen wir aus so wenigen Einzelkomponenten wie möglich, um bei minimalem Materialeinsatz und somit geringem Gewicht die maximale Funktionalität und höchste Stabilität sicherzustellen.

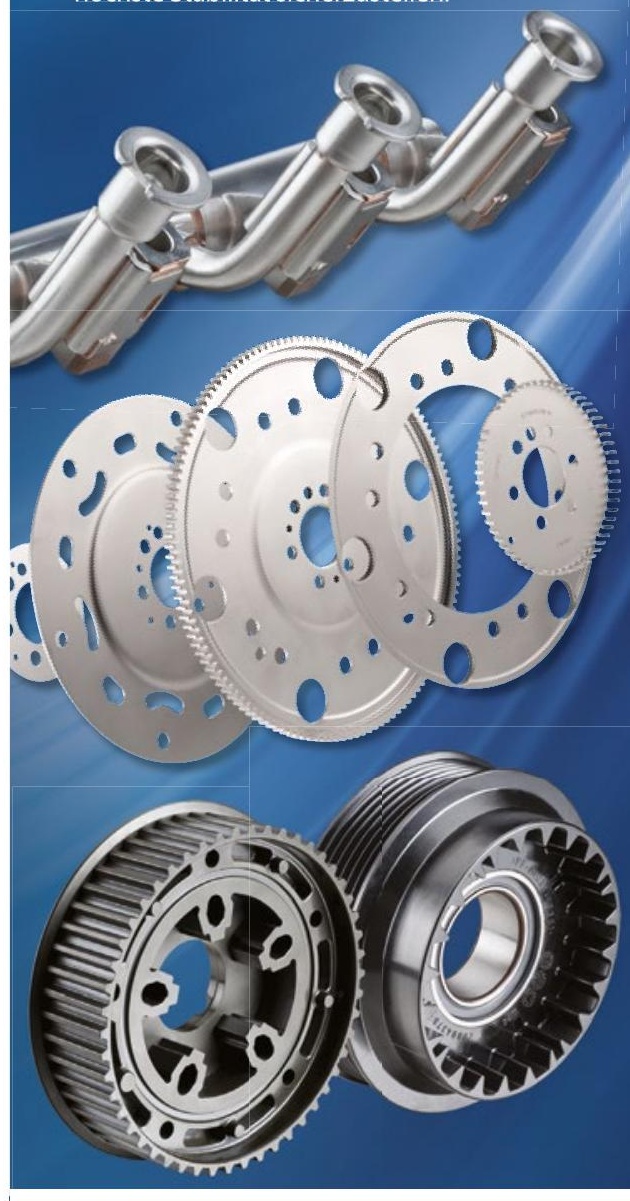

Winkelmann Powertrain Components GmbH + Co. KG Schmalbachstraße 2, 59227 Ahlen Tel: +49 (0) 2382 856-0

winkelmann-automotive.com 